\title{
Spatiotemporal Variations in Terrestrial Water Storage and Its Controlling Factors in the Eastern Qinghai-Tibet Plateau
}

\author{
Yu Zhu ${ }^{1}$, Shiyin Liu ${ }^{1}$, Miaomiao Qi ${ }^{1}$, Ying $\mathrm{Yi}^{1}$, Wanqiu $\mathrm{Li}^{2}$, Muhammad Saifullah ${ }^{1}$, Sidou \\ Zhang $^{1}$, and Kunpeng $\mathrm{Wu}^{1}$ \\ ${ }^{1}$ Yunnan University \\ ${ }^{2}$ Shandong University of Science and Technology
}

May 5, 2020

\begin{abstract}
The eastern Qinghai-Tibet Plateau (EQTP) is the source regions of the Yangtze, Lancang/Mekong, and Nujiang/Salween rivers. Their hydrologic dynamics are key to water resources in the downstream area. An analysis of the spatiotemporal variations in terrestrial water storage (TWS) in this region has practical significance for regional social prosperity and the stability of the ecological environment. In this paper, the monthly GRACE Level 2 Release 6 (RL06) products were employed to invert TWS changes from April 2002 to August 2016, and dominant factors contributing to the changes in TWS in subbasins and decreasing and increasing areas were analyzed systematically. We concluded that. (1) the TWS in EQTP showed a slight decreasing trend from 2002 to 2016 with the obvious spatial heterogeneity. The TWS trend ranged from $-0.94^{\sim} 0.91 \mathrm{~mm} / \mathrm{m}$ with a decreasing trend in the southwest and an increasing trend in the north. The pattern in TWS is approximately similar to the change in soil moisture $(\Delta \mathrm{SM})$. (2) the decrease in TWS may be attributed to the increase of evapotranspiration, which has approximately increased by 53\%, and increase of glacial ablation and reduction of precipitation in EQTP. Moreover, the decrease in evapotranspiration can partly explain the increase in areas with TWS increase. However, we speculated that the lakes supplemented by glaciers are the main cause of the regional changes in TWS. Glacial ablation is the dominant factor in the region where a substantial decrease in TWS is observed (an approximately $69 \%$ contribution). (3) The decrease in TWS mainly occurs in summer and is mainly due to the increase in evaporation in summer because of warming, increase in wind speed and decrease in the relative humidity. (4) the mass balance of glaciers was estimated indirectly based on the GRACE results, but a further study is needed to determine the specific process.
\end{abstract}

\section{Hosted file}

manuscript20200130.pdf available at https://authorea.com/users/295047/articles/423621spatiotemporal-variations-in-terrestrial-water-storage-and-its-controlling-factors-inthe-eastern-qinghai-tibet-plateau 

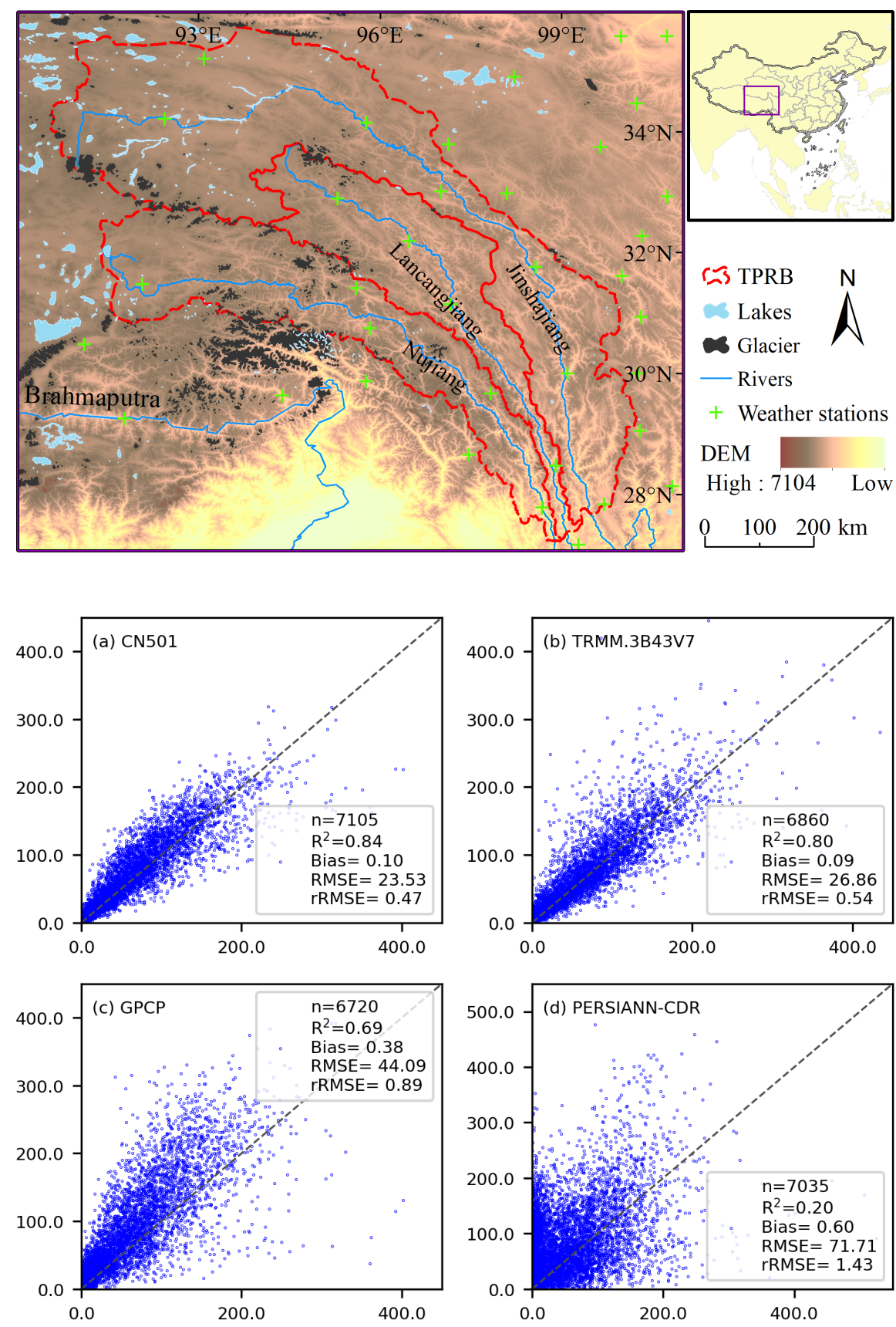

Precipitaion $(\mathrm{mm})$ from different models on the vertical $Y$-axis against gauge precipitation $(\mathrm{mm})$ on the horizontal $x$-axis

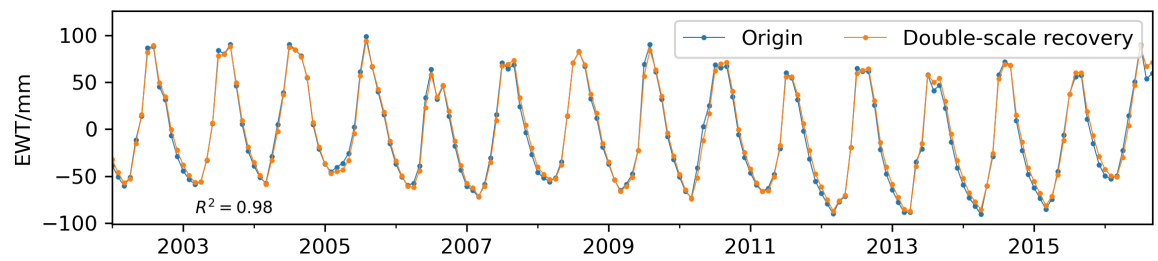



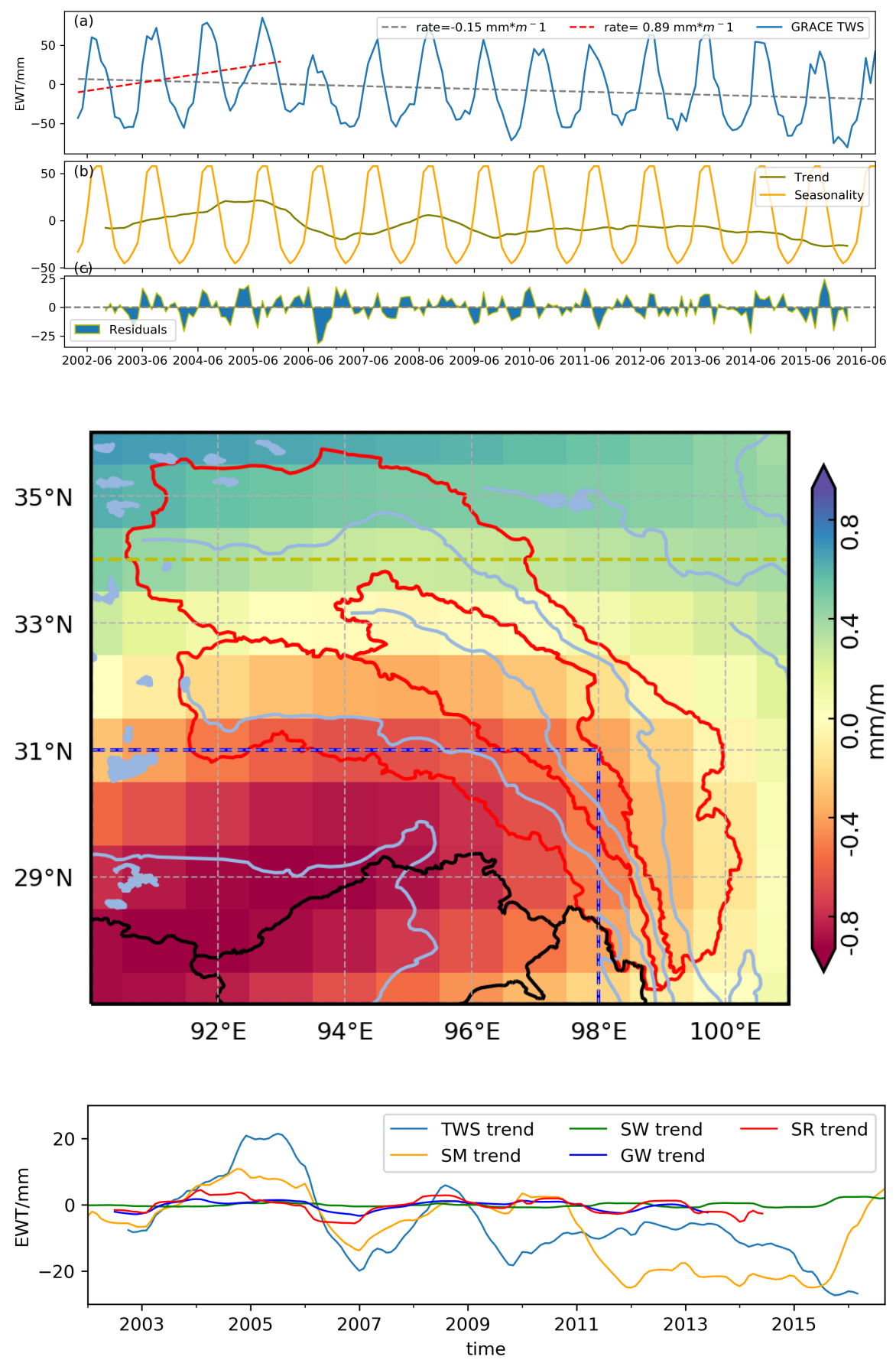

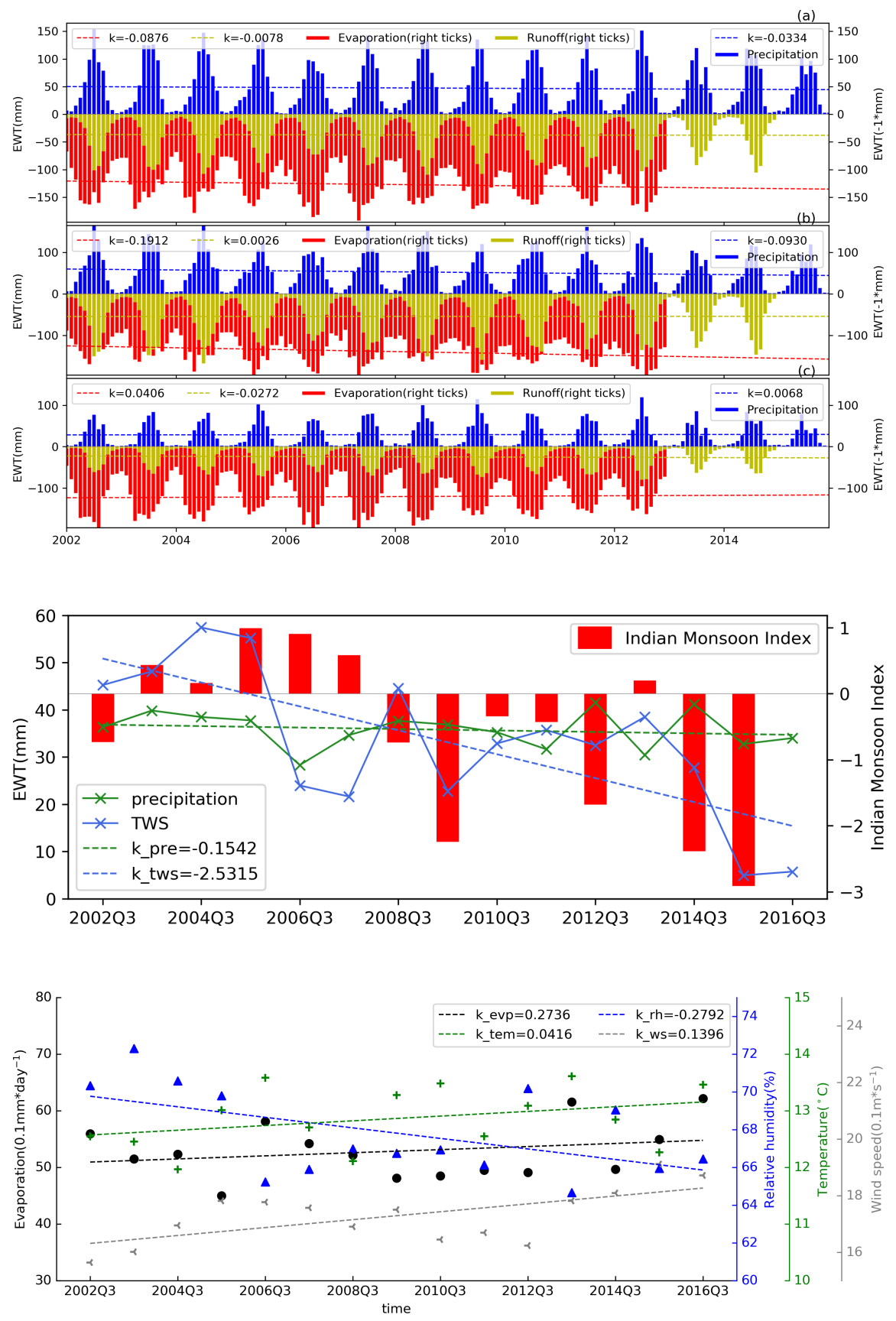